City University of New York (CUNY) CUNY Academic Works

2020

\title{
The Communicative Function of Adjective-Noun Order in English
}

Kelli Hesseltine

CUNY City College

Joseph C. M. Davis

CUNY City College

\section{How does access to this work benefit you? Let us know!}

More information about this work at: https://academicworks.cuny.edu/cc_pubs/811

Discover additional works at: https://academicworks.cuny.edu

This work is made publicly available by the City University of New York (CUNY).

Contact: AcademicWorks@cuny.edu 


\title{
The communicative function of adjective-noun order in English
}

\author{
Kelli Hesseltine and Joseph Davis* \\ Department of Learning, Leadership, and Culture, The City College of New York, New York, NY, \\ USA
}

The problem undertaken here is to account for the relational placement in English of words traditionally known as adjectives and nouns. Two distinct orders are examined as signals of discrete meanings: one where the characterizing word is preposed to the characterized word, as in long hair, and the other where it is postposed, as in hair long. Distribution of the two signals in attested text is accounted for under the hypothesis that an Assertion of Characterization is made WEAKER or STRONGER, respectively, through this word order. With these meanings, a writer draws a distinction between Characterization the writer assumes the reader will receive as uncontested and so requires WEAKER Assertion and Characterization which is selected out of an array of particularly relevant possibilities and so requires STRONGER Assertion.

Keywords: adjective; noun; word-order; English; characterization; modification

\section{Introduction}

Supplementing previous studies of modification in English involving words typically classifiable as adjectives and nouns, this paper proposes a semiotic hypothesis for the order of those two, for example the pair long hair and hair long. Under this hypothesis, the two orders of the two lexical items function as discrete grammatical signals (cf. Saussure's signifiants), each signal conventionally encoding a meaning (cf. signifié). ${ }^{1}$ The two mutually opposed meanings are used, along with other linguistic resources, to structure communication in discourse.

Appreciation of this hypothesis assumes two very basic and general features of human language: that linguistic units exist in various types, and that linguistic units occur in some order. Each of those two underlying assumptions will now be briefly examined.

In general, grammatical signals - as distinct from lexical items, which are always morphological - exist in three types: the morphological (e.g. the $-s$ of hair-s), the null (the zero of hair-Ø), and the positional (long hair / hair long). This three-way classification has a long history in linguistics - at least since Saussure (1915/1972) - and it continues as a useful typology in linguistics today. This paper concerns an instance of that third type of grammatical signal, order or position. ${ }^{2}$

Speech (and conventional written text too) is a phenomenon that develops through time, and so it is unavoidable that linguistic units occur in some order. Those orders may be: fixed and presumably inherent in the structure (e.g. the [z] at the end, not the beginning, of the lexical item hair); fixed and presumably motivated by some

*Corresponding author. Email:jdavis@ccny.cuny.edu 
consideration of cognition or processing (e.g. apples and grapes, not and apples grapes); variable and presumably motivated by some consideration such as iconicity (e.g. if $X$ then $Y$ ); or variable and arbitrary, conventional, and thus available for the communication of different messages. That last status is examined here: The order of the words considered here is asserted to encode a constant semantic content, a content with which language-users can craft messages. That is, the order itself - the order of the two lexical items - is held to be a signal of a meaning.

The hypothesis proposed in this paper has been devised in order to account for our observed distribution of the two orders in attested discourse. Accounting for that distribution is the purpose of this paper.

\section{The hypothesis}

Characterization of an entity occurs when a language-user provides description to indicate the entity's pertinent traits. The user of English makes a decision as to whether the Assertion of this Characterizing information needs more or less emphasis. Those two degrees of intensity are signaled by two contrasting word orders. The selection draws a distinction between (1) Characterization the author judges that the reader will share as uncontested and so requires WEAKER Assertion and (2) Characterization that the author selects out of an array of relevant possibilities and so requires STRONGER Assertion. ${ }^{3}$ The meaning WEAKER Assertion of Characterization is signaled by the order represented here as AB, as in long (A) hair (B). The meaning STRONGER Assertion of Characterization is signaled by the order represented here as BA, as in hair (B) long (A). With these meanings, an author directs the reader's reception of the Characterization, and such direction helps to structure a text.

The hypothesis can be represented formally as in Figure 1. In the figure, the semantic substance, or domain, of Assertion of Characterization is exhaustively divided into two mutually opposed meanings, WEAKER and STRONGER. The meaning WEAKER is signaled by the order represented by AB after a determiner, as in my long hair. ${ }^{4}$ The meaning STRONGER is signaled by the order represented by BA, as in hair (...) long. In each case, the referent of one word, the "B," is Characterized by the other word, the "A." For convenience, we refer to the two orders as AB and BA.

That is our hypothesis.

For WEAKER Assertion of Characterization, a Characterizing word (A) precedes the Characterized word (B) (e.g. long hair) to tell the reader that the given attribute requires no special Assertion. Other, alternative and competing descriptions are not relevant to the author's point..$^{5}$ The Characterization should be received as

\begin{tabular}{|c|c|c|c|}
\hline Semantic substance & meanings & $\underline{\text { signals }}$ & example \\
\hline Assertion of & WEAKER & [det $] \mathrm{AB}$ & my long hair \\
\hline of B by A & STRONGER & BA & hair long \\
\hline
\end{tabular}

Figure 1. The hypothesis: the grammatical system of Assertion of Characterization. 
uncontroversial or uncontested. A WEAKER Assertion of the Characterization is adequate because the author has directed the reader to accept the information as contextually established or obvious.

For STRONGER Assertion of Characterization, the Characterizing word (A) is postposed to the Characterized word (B) (e.g. hair long), and the author communicates a more subjective and individualized perspective. The Characterizing trait (A), selected out of a relevant array of possible others, needs extra emphasis and so STRONGER Assertion. The Characterization must be Asserted more forcefully to call it to the reader's attention so that the writer's point of view can be embraced in order for the reader to arrive at the intended message.

\section{Methodology}

The analyst, obviously, cannot appreciate this difference in grammatically signaled meaning through intuition on the two words in isolation, nor even, often, in an isolated sentence. Language-users make the choice within a context and on the basis of their communicative needs. The analyst would fail to perceive the difference were it not for a reliance on context in the analytical procedure and through an openness to considering the language-user's communicative intent. ${ }^{6}$ For that reason, we rely upon attested discourse, typically at a level above the sentence.

The discourse used for this study encompasses published and unpublished literature and transcribed speech, including novels, news stories, social media, and an electronic corpus. In practice, we often find published literature to be more analytically useful to us than spontaneous speech. Typically, a writer and a reader do not share the same space and time, and so a writer typically furnishes - does not assume - whatever context will facilitate communication. Indeed, the writer of a work of fiction determines autocratically just what information and what context will be provided to a reader. That provision of context helped us to develop a hypothesis for a difference in meaning between the two orders.

In our analysis, we rely upon observation of attested usage rather than intuition on constructed text. Our data cannot be fabricated or manipulated by us. Given a piece of authentic usage, one might, of course, exercise one's intuition regarding any imaginable alteration of that datum. Our methodology, however, is instead to take the data as given and, when analytically necessary, to seek out another authentic example, within its context, that will meet our needs. Our data come from published texts or transcript of speech - or, as it is often termed, "naturally occurring" language. For instance, one might observe an attested sequence such as I like my long hair and exercise intuition on that datum versus I like my hair long. By contrast, we would analyze the communicative effect of an observed sequence such as I like my long hair, taking advantage of its surrounding context, and seek out an attested example such as I like my hair long and take advantage of its surrounding context.

By accumulating such attested examples into a large data set of no predetermined size, we develop a hypothesis. (Like every hypothesis, of course, ours is subject to rejection on the basis of disconfirming data. Also, as with many hypotheses, we at times use quantitative data to support our hypothesis.) In practice, our collection of data began with Patchett (2011) and grew as needed, eventually encompassing both written and spoken usage. We have no reason to believe that our hypothesis applies to one medium and not the other, though we make no claim at all concerning data that we 
have not examined (such as, obviously, varieties of English with diverse grammatical features), nor concerning relative frequencies across genres (including published fiction and spontaneous conversation).

\section{Review of literature}

The literature reviewed in this section can be divided into three categories: that which has to do primarily with the lexical content of adjectives; that which has to do with the information structure and textual cohesion of discourse; and that which, as with the present study, treats the relative order of words as a meaningful signal itself.

\subsection{Studies that are primarily lexical, only secondarily grammatical}

Much work has been done involving the lexical content of adjectives as they function, through the modification of nouns, in a larger phrasal interpretation. That work is of tangential relevance here since the present study deals not with lexical content but with positional signaling (by lexical items).

Among those studies, Quirk and colleagues (1985) classify adjectives as "central" or "peripheral" based on versatility of position: partly on whether or not, respectively, a given adjective can appear in predicative position. The adjective soft would be classified as "central" because it can appear in predicative position (e.g. The pillow was soft), and the adjective utter as "peripheral" because it cannot (*The devastation was utter). In this classification (as exemplified by Davidse \& Breban 2019: 328-329), the "central" adjectives are the referent-descriptors (or "descriptive modifiers" or "epithets") (as in unpleasant procedure). The "peripheral" adjectives include the "classifiers" (congressional procedure) and the "secondary determiners" (the same procedure). Thus, an individual adjective is classified according to the communicative function typically associated with its use; by contrast, we do not classify individual lexical items but analyze position per se.

Relying additionally on formal computational semantics and on intuition, Boleda and colleagues (2013) also examine adjective-noun phrases (e.g. white dress) in terms of their lexical sense. Among several types of adjective-noun phrases for which they intuit the meanings, the type Boleda et al. identify as "intentional" (represented by alleged criminal, where the referent is not necessarily, truthfully, a criminal at all) is acknowledged as the most difficult to analyze, in isolation, vis-à-vis truth value. As with Quirk and colleagues (1985), above, so Boleda and colleagues (2013) is of limited relevance here given our interest in order as a signaling device.

Paradis (2008) shares this focus on lexical content and so is of only tangential relevance here. Paradis (2008: 332-333) does recognize, however, that a particular modifier may serve in the "foregrounding and backgrounding and subjectification" of information. Furthermore, Paradis also shares our interest in language use and perceives the benefit to the analyst of a cognizance of context, as opposed to sentences in isolation. For Paradis (2008: 319, crediting Gardenfors 2000) - in line with Cognitive Grammar and compatible with our own view - "Meanings are in people's minds. They are not independent entities in the external world."

Taylor (1992) also treats adjective placement within the framework of Cognitive Grammar, but Taylor, much like the formalists, relies upon constructed sentences, 
with their syntactic components, in isolation and attempts to classify interpretations according to a logical semantic scheme. Taylor proposes that "Adj $N$ expressions" arise differently out of attributive and predicative syntactic positions and focuses specifically on the multiple lexical senses of the adjective old (e.g. old girlfriend) in relation to its position in a sentence. Acknowledging the "choice of interpretation" offered by a speaker to a listener (p. 21), Taylor recognizes that a listener must "take into consideration, not only objectively ascertainable facts" but also must consider "conventionalized, culturally-bound knowledge" (p. 22). In the present study, a language-user's stock of relevant considerations must be open beyond the conventional to include as well the idiosyncratic.

Asher and colleagues (2016) share with the formalists an "algebraic interpretation" (p. 703) and a reliance upon intuition as an analytical technique. Like the investigators surveyed above, Asher et al. are interested in lexical content and in how the intuition-based interpretation of words used together may differ from the interpretation of each word taken separately. Asher et al. do share with the present study an appreciation for attested language-use data, yet they make use of a corpus while our data are not restricted to any particular corpus.

Davidse and Breban (2019) work within a theoretical framework (cognitive-functional) that shares much with ours, particularly in terms of its being semiotic. They also, like us, rely on attested usage. They see the position of an adjective as a direct result of that adjective's "meaning in context" (p. 364); thus, as with works reviewed above, the interest is primarily lexical, only secondarily grammatical. Moreover, their "context" consists mostly of the single isolated sentence that contains the adjective-noun complex that they cite, not the wider discourse in which that data point is observed.

For Davidse and Breban (2019), interest lies almost entirely in the ordering of prenominal adjectives among themselves. They view the immediate post-nominal order (e.g. heir apparent) as occurring only "rather exceptionally and under specific conditions" having mainly to do with "aspects of information structure" (p. 344). As for the predicate adjective position, it factors into their functional classification of adjectives: one class (viz., the noun-intensifier) never occurs as "predicate adjective." In sum, Davidse and Breban (2019) do not investigate the distinction between prenominal and post-nominal positions as a semiotic matter in its own right; their analytical aim is different from ours.

The goal of the present paper, again, is not to categorize the various types of adjectives by their communicative functions or lexical content, nor to catalogue the possible interpretations of strings of adjectives - indeed, we do not even need the distinction between adjective and noun - but instead to account for the relational placement, in attested discourse in English, of words involved in a simple communicative relation of Characterization. ${ }^{7}$ We do not assume a referential logical semantics. We rely upon context rather than intuition on isolated sentences. To provide that account of observed distribution, we posit two meanings that are signaled by opposing word orders.

\subsection{Studies of discourse and how it relates to grammar}

Within Information Structure, Prince (1981) demonstrates that a speaker, in discourse, must often take into account his or her guess as to a reader's assumptions. Similarly, 
much of our discussion of a writer's choice between our two meanings (WEAKER and STRONGER Assertion of Characterization) requires acknowledgement of such assumptions in discerning whether a certain Characterization will more effectively be conveyed with an $\mathrm{AB}$ or a BA signal. Furthermore, Prince does identify many instances of such choice as a writer's decision that a hearer will be able to predict the writer's usage, or that an idea will be salient in the reader's consciousness, or that it will be inferable. However, unlike linguists in that tradition, we do not assume a distinction between sentence-based "linguistic" and extra-sentential "nonlinguistic" systems, and we do not take for granted the taxonomy of linguistic forms associated with structural and generative grammar. That is, we do not take the sentence and its parts as the relevant units of analysis. We do not attempt a taxonomy (binary, ternary, or continuous) of a language-user's mental states as reflected in discourse output.

Our hypothesis of meaningful signals distributed throughout a text is consistent with the view of language as an instrument of human communication (e.g. Diver 1995/2012). It turns out that, in that account, while we do find that writers may take a reader's assumptions into consideration, writers do not, pace Prince, necessarily structure their discourse so as to "meet" the reader's assumed needs but rather may, for instance, actually impose a particular communication (in our case, a particular Characterization).

As in the study of Information Structure, so too in the study of textual cohesion the object of inquiry is something other than linguistic mechanisms themselves; the object of inquiry for Halliday and Hasan (1976) is cohesion in a text, which is "not a grammatical unit" (p. 1). And as with the study of Information Structure, the study of cohesion takes for granted, as relevant to analysis, the construct of the sentence, "the highest structural unit in the grammar" (p. 28), and its parts. So, for instance, one might study how cohesion in a text can be effected by the interpretation of "the verbal substitute $d o$ " (p. xiii). ${ }^{8}$ Our analysis does sometimes take note of aspects of cohesion in a text and how our proposed meanings might contribute to that effect, but the aim of our analysis is not cohesion per se but rather the observed distribution of grammatical units (viz. the orders of certain words).

Halliday and Hasan (1976: 1, 8) do use as data "language in use," "spoken or written, of whatever length." For them, this entails disregarding a grammatical unit the sentence - that they accept; by contrast, we do not even accept the sentence as a grammatical unit to begin with - though it may be a unit of discourse (Diver et al. 2012: 430-437). And like Halliday and Hasan (1976), we too are interested in, inter alia, the question of "what are the external factors affecting the linguistic choices that the speaker or writer makes" (p. 21). For us, those linguistic choices include the choice between the two grammatical meanings that we posit for word order. In making a choice, a language-user may indeed take into consideration aspects of the "situation" (Halliday \& Hasan 1976: 21) or the "scene" (Diver 1975/2012: 48-49).

\subsection{Studies of the grammatical signaling of meaning}

Because all the preceding analyses deal primarily with something other than the grammar itself - instead with lexical content or with the structure of text - the analyses that are directly relevant to the present analysis are few. Two, Bolinger's and Diver's, merit particular attention. 
Bolinger (1967) offers an early examination of adjective-noun vs. noun-adjective order, noting "a clear functional difference between attributive modification and predicative modification" (p. 1). Bolinger's theoretical orientation, much like ours, is that language is a communicative instrument comprised of signaled meanings, and that order can be a signal of a meaning. Note that communication is a subjective activity; in Bolinger's words, "A speaker with a mind to exaggerate can do almost anything" (p. 10). In Bolinger's words, however, "an adjective develops two distinct senses related to its positions" (p. 4). We would say rather that the positions of a word relative to another word represent not two senses of the one word but two opposing signaled grammatical meanings. Bolinger's proposed meanings - having to do with "temporal spread" (p. 1) - furthermore, do not stand up to scrutiny in actual text. ${ }^{9}$

The recognition, by several scholars above, that language in actual usage does not necessarily reflect the facts of the real world, represents a step away from a referential, truth-conditional view of language towards a view of language as a tool of human communication. ${ }^{10}$ Often, what humans say is not a direct reflection of the real world but instead a subjective comment that may at best be influenced by that referential reality. In this vein, the three-way distinction made by Diver (1975/2012: 4854) among what he called scene, message, and meaning is useful, and it is pertinent to this study. ${ }^{11}$

For us, as for Diver, one thing - the scene - is "the non-linguistic context, including individual objects, apropos of which one speaks." Representational meaning (as in Bloomfield's salt $=\mathrm{NaCl}$ ) constitutes an attempt to match linguistic form onto the scene. That attempt would fail utterly in our case, since both long hair and hair long can refer to the exact same epidermal outgrowth. Another thing - the message - is "the idea one communicates apropos of the scene." Traditional notions, including many that persist in modern linguistics, constitute unsuccessful attempts to map linguistic form onto possible messages. For instance, hair long can contribute to a message of temporary status, as in On a lark, I grew my hair long. But so too can long hair, as in During that brief fling, I loved having long hair. Neither scene nor message is the linguistic analyst's proper goal, because neither accounts for the distribution of the linguistic forms (the orders hair long vs. long hair). And so yet a third thing is what Diver called the linguistic meaning: one of "the relatively small number of communicative units actually provided by an individual language, these being indicated by specific signals of that language."

The present study proposes two meanings in Diver's sense of that term: the communicative units signaled in English by the two orders represented by long hair (order $\mathrm{AB}$ ) and hair long (order BA). These linguistic meanings - these encoded semantic values - in context with other semantic values - including the semantic values of the lexical items - can be used by speakers and writers to express whatever message they choose. And that message may or may not closely correspond to referential reality. The scene is not the message is not the meaning. Long hair and hair long refer to the same thing: one scene corresponding to two linguistic forms. And one language-user might communicate approval of a person by saying Your hair is long, while another person might suggest disapproval by using the very same sentence: two messages (approval, disapproval) communicated by the same utterance. The task for the analyst is not to map, by intuition, the elements of language to a referential scene, nor to account for the messages speakers choose to express, but instead to account for the observed distribution of a language-user's signaled meanings: for 
instance, the distribution in discourse of the orders long hair and hair long. ${ }^{12}$ That is the goal of this paper.

Eschewing the traditional terms used by previous researchers - and indeed their entire theoretical apparatus - Diver (1982), summarized in Huffman (2001) and Reid (2006), credited "word order signals" with an English language-user's ability to differentiate referents either FROM OTHERS (signaled by the order AB) or FROM SELF (signaled by the order BA). Distinguishing between these orders, Diver recognized the AB signal's ability to "differentiate the referent of the word... FROM OTHER POSSIBLE REFERENTS of that word" (Reid 2006: 23). For example: He found the guilty man versus He found the man guilty. In the first, the word guilty appears to distinguish the one man from other men, while in the second, guilty appears to distinguish the one man from himself, that is, his later state from his earlier state. Diver's work (collected in Huffman \& Davis 2012) provides foundational ideas as well as the methodology for our own research. ${ }^{13}$ Diver's particular hypothesis for the AB and BA orders, however, somewhat like that of Bolinger's, turns out not to be adequate to account for distribution in actual discourse, as we shall see. ${ }^{14}$

Though original, the present analysis arises within a framework, the Columbia School, that originated over fifty years ago at Columbia University and continues today. For previous Columbia School analyses involving order (or position) as a grammatical system comprised of signaled meanings, see: Klein-Andreu (1983), Gildin (1989), Huffman (2002), Diver and Davis (2012: 239-245), Davis (2017b: 83-86), and Stern (2018).

Other grammatical systems that have been posited for English, consistent with our theoretical orientation, include those of Number (singular-plural), Status of Differentiation (articles), Attention (demonstratives), Focus (subject-verb order), Focus Number (verb number), Time (tense), Probability (mood), Vividness (participles), and Degree of Control (case role). See Huffman (2001) and Reid (2006) for summary references to some of these. For particular analyses of English grammatical systems, see Reid (1991), Huffman (2002), Reid (2011), Diver and Davis (2012: 239-245), and Stern (2018).

\section{Analysis}

\subsection{WEAKER Assertion of Characterization (signal AB)}

The AB order Asserts a Characterization that, in the writer's or speaker's view, should be accepted by the reader or listener in a way that establishes an almost cooperative knowledge or a sort of club mentality. When the Characterizing word (the adjective) precedes the Characterized word (the noun), the order communicates that the given Characterization requires no special Assertion. The author's choice suggests that other alternative, competing descriptions are not relevant. Subjectivity (always present in language use) is downplayed, and the information is provided as obvious or contextually consistent.

Below is a presentation of various discourse circumstances that we have found to be associated with WEAKER Assertion of Characterization. While the sundry categories and passages below are representative of the meaning WEAKER Assertion of Characterization and cover the varied circumstances and types of $\mathrm{AB}$ examples we have found, the reader should not imagine that this list, nor the one for BA to follow later in this paper, is exhaustive, nor that its members are mutually exclusive. Every example is unique. The rationale for organizing examples in this way simply 
as a useful heuristic, along lines that are in no way discrete analytical constructs, is discussed in Diver (1990/2012: 78), Huffman (1997: 83-85), Stern (2006: 183), and Davis (2017b: 225-230).

\subsubsection{Characterization that the reader already knows}

At times, an author constructs an episode in a text through the consistency and even repetition of the information and Characterization provided. Repeating what a reader already knows - the reader having already been told - can help to keep a reader oriented as a text progresses.

In Example (1), the fictional June's Characterization as little is Asserted twice both times preposed - within a short span of text.

(1) June, like many little (A) girls(B), was partial to soft things ... . Then little(A) June

(B) took sick and laid $[\mathrm{sic}]$ in her bed like a dull penny. (Patchett 2011)

Previous context for the passage has already established June as someone's young daughter; the subjectivity or relativity of her being little is therefore downplayed at this point in the text - she isn't being distinguished from other Junes or assessed for her height. Both the repetition of the information and its placement before the words it describes (girls, June) reinforce the fact that this Characterization is contextually obvious. ${ }^{15}$ The author directs the reader to accept it as given and undisputed. It requires WEAKER Assertion. (Note that it makes no difference whether the B is a "common" or a "proper" noun.)

Likewise, context makes clear in Example (2) that the Characterization provided by the AB signal is well-established and known by the reader and thus needs no emphasis or special attention:

(2) Mme Delacour choked to death on a chicken bone.

Delacour ... rendered up excuses to his $\operatorname{dead}(A)$ wife $(B)$, and entered into an arrangement with a maid at the baths, whom he visited once a week. (Barnes 2004)

In this short story, the narrator mentions the death of the character's wife at least six times. The description of her as dead, though germane in the unfolding of events here, is not new or unknown to the reader. The Characterization requires WEAKER Assertion because it does not contradict the expectations or circumstances provided as a matter of course within the sequence of events. It simply builds upon the already established circumstances of the scene in service to the narrative. With his excuses made to the dead wife, Delacour feels free to initiate a sexual relationship with another woman.

\subsubsection{Characterization that the reader can easily assume or imagine}

Authors also often employ the AB signal to convey a Characterization that, while not previously contextually explicit, still does not require more forceful Assertion because it draws upon the reader's ability to assume or imagine the relevance or likelihood of the information. 
In example (3), any person familiar with the singer Robert Plant or his band Led Zeppelin, or aware of the cultural associations of the "quintessential" rock-singer persona, is prepared to understand and accept the writer's subsequent and thus more weakly asserted Characterizations of Plant's attributes:

(3) He was the quintessential hard rock front man in what was for a time the biggest hard rock band on the planet: Robert Plant, lead singer of Led Zeppelin, $\operatorname{long}(A) \operatorname{hair}(B), \operatorname{bare}(A)$ $\operatorname{chest}(B), \operatorname{tight}(A)$ pants $(B)$, howling his way through albums and arenas. (Brown 2017)

The ABs here elaborate on the features of a "quintessential hard rock front man" and require only WEAKER Assertion within this context.

Example (4) below contains Characterization that requires WEAKER Assertion because the writer can assume that many readers can be relied upon to connect the specific time and place in the example to the typical events and experiences associated with them. The Characterization summarizes the writer's experience of summer, leaving the specific details up to the reader to imagine:

(4) From 1933 to 1941 ... I spent nine summers in a big white house in the Adirondacks. ... The long, $\operatorname{classic}(A)$ American $(A)$ summer $(B)$, which began with our arrival a few days before the Fourth of July and lasted through Labor Day, became the whole of life for me. (Tomkins 2004)

This passage occurs at the very beginning of a New Yorker article about Tomkins's summer memories. The details of the scene - summer "in a big white house" in the mountains, the celebration of two culturally familiar holidays ("the Fourth of July and ... Labor Day"), and a past for which the author is nostalgic ("the whole of life for me") - prepare the reader then to receive Tomkins's Characterization of his summer as classic American. ${ }^{16}$ Though each family's summer rituals might be different, Tompkins's are positioned here as typical or familiar enough that he can assume any readers in his audience will reliably recognize such summers - they'll get his drift. The Characterization, and its consistency with the surrounding details, does not need especial highlighting as the narrative progresses.

\subsubsection{Characterization the writer expects the reader to take on the writer's authority}

Consider Example (5):

(5) Now I was the sous-chef at one of the best( $A$ ) Italian restaurants $(B)$ in New York, with an inside track-I was assured - to becoming the executive chef at the ultracool, Philippe Starck-designed, Schragger-owned hotel. It was a dazzling development. (Bourdain 2000)

Anthony Bourdain, a man famous for his food expertise, recalls an important moment in his education as a chef. His authority for cooking and assessing food is well established, both in the full memoir and in the example's immediate context: he is the "sous-chef" with "an inside track" to be an "executive chef." Readers, in receiving this information, can acknowledge that the author is claiming authority and can understand that the author (rightly or wrongly) assumes that everyone should agree with the Assertion best Italian restaurants. 
In a similar way, a Characterization that is consistent with a perspective that the language-user assumes to be shared within a group might also require WEAKER Assertion. The preposed order helps establish the description as well-known or uncontroversial within the group. In the following example, Donald Trump, in 2016, tweets out his assessment of Hillary Clinton, who was then running against him in the U.S. presidential election. He employs a descriptor that, over the course of his campaign, became her identifying nickname, one that was echoed often by his ardent supporters:

(6) Crooked (A) Hillary Clinton (B) is unfit to serve as President of the U.S. Her temperament is weak and her opponents are strong. Bad judgement! (Trump 2016)

Trump's Characterization of his political opponent as crooked is preposed because he wants crooked to be a designator of Clinton shared by his audience; it was an oftrepeated moniker during his rallies. His use of the term in this way established his expectations for the group-mentality he would share with his audiences regarding Clinton's character. By contrast, his subsequent assessment of her qualifications for the presidency, which is his real point here - that she is "weak," while her opponents are "strong" - is highlighted more forcefully; see below on STRONGER Assertion of Characterization.

\subsection{Stronger Assertion of Characterization (signal BA)}

At times in a text, the author acknowledges a subjective and individualized perspective in selecting the salient traits that characterize an entity. At such times, a particular trait, selected out of a relevant array of possible other traits, needs extra emphasis, and the meaning STRONGER Assertion of Characterization, signaled by the order $\mathrm{BA}$, directs the reader to embrace the writer's subjective point of view in order to arrive at the intended message.

With the meaning STRONGER Assertion, the author instructs the reader to pay extra attention to the Characterization, as it is being Asserted in service to the author's larger message. This is an emphasis the writer evidently believes the reader needs more forcefully in order to appreciate the message fully. In some instances, such Characterization, having not previously been made situationally explicit, is surprising and may even run contrary to expectations already established in the context. In other instances, the Characterization may confirm, sum up, and thus highlight an attribute through its consistency with the scene already described, and for this reason the writer calls it to the forefront of the reader's attention. Whatever the degree to which the reader has been prepared to accept it, the Characterization is important and requires more emphasis so as not to escape notice.

What follows here is a presentation of various discourse circumstances associated with STRONGER Assertion of Characterization, as was done above for WEAKER Assertion of Characterization.

\subsubsection{Characterization that results in thematic foregrounding of details}

At times, the author renders certain Characterizing information more prominent with the BA signal in a way that is instrumental to the thematic development, or underlying significance and purpose, of a text. Traits that otherwise might have escaped the 
reader's notice are foregrounded and emphasized due to their pertinence to the message.

Example (7) comes from a review of a memoir by Esmeralda Santiago whereby the author of the review, herself intimately familiar with Puerto Rico, celebrates the surprising vibrancy of Santiago's Puerto Rico in a review titled "In Praise of Esmeralda Santiago." The example contains a contrasting BA and AB:

(7) There are books that launch you into $\operatorname{worlds}(B)$ unimaginable $(A)$... . Santiago gave my imagined (A) Puerto Rico(B) depth and historical grounding. (Rivera 2019)

Context makes clear the reviewer's need to Assert strongly the Characterization of Santiago's Puerto Rico as unimaginable because, for her, the memoir "illuminat[es] a place and a family dynamic I thought I already understood" but which was actually "not the one I knew." As the child of Puerto Ricans, the reviewer's initial understanding of Puerto Rico - "an idyllic place" formed from her childhood visits - isn't complete until she reencounters it in unexpected ways in Santiago's text.

\subsubsection{Characterization that advances the narrative significantly}

The need to emphasize a thematic element of the whole text is not the only reason to direct a reader's attention to a salient Characterization. The meaning STRONGER Assertion of Characterization (BA) can also be employed to highlight a detail that is especially instrumental in advancing the narrative at a crucial point. Such is the case with Example (8):

(8) Luckily there was a $\operatorname{door}(B)$ unlocked $(A)$ beside a large truck that was backed up to a loading bay. We silently entered. (Barwell 2012)

In (8), the door unlocked allows the children to enter the loading bay, a circumstance that is identified, moreover, as "lucky" and which enables them to proceed with their adventure. The information provided by the Characterization is crucial to the progression of events, and so the meaning STRONGER Assertion is employed to make sure it does not escape notice.

\subsubsection{Characterization that accompanies a change of state}

The STRONGER Assertion of a Characterization through the postposing of essential details often facilitates the advancement of a narrative by highlighting a change in state. This situation is represented by Example (9):

(9) A natural brunette, Lily James was happy to dye her hair (B) blond (A) when she landed the role of Lady Rose MacClare on the hit drama "Downton Abbey." She just had no idea how much her makeover would change her life. (Yahr 2014)

In (9), actor Lily James's hair becomes blond, and this spotlighted Characterization, new to James - a "natural brunette" - renders subsequent events possible: She lands a big role, her makeover "change[s] her life." 
In general (pace Diver 1982), it is not the function of the BA order to differentiate an entity from itself. It may be true, in (9), that Lily James's hair used to be brown and is now blond, thus is different from its former self, but that inference is not localizable in the meaning of the collocation hair blond; it involves at least the words natural and dye. Rather, the Characterization of the hair as blond is given a STRONGER (not a WEAKER) Assertion in order to facilitate advancement of the narrative, the lurch from professional doldrums to stardom. Moreover, an inference of change of state is not consistently applicable with BA. Back in Example (8), for instance, there is no suggestion - nor is it at all relevant - whether the door used to be locked or later became locked. There can be comparison or change associated with either order, and with neither order is comparison or change the point.

A striking distributional consequence of the opposition between the two meanings WEAKER and STRONGER Assertion of Characterization can be seen in the following count (Table 1). The count shows the relative change in the frequency of the two meanings from the year 2016 to 2017, as seen in the order of the two words President and Trump. A chronological search of the Corpus of Contemporary American English (COCA) was conducted for the two phrases President Trump and Trump President, that is, for the order of the proper name Trump and the title President. ${ }^{17}$ In 2016 all of which unfolded before his inauguration - there was a stronger communicative need to Assert President as a way to Characterize Donald Trump (thus Trump Presi$d e n t=\mathrm{BA})$. For most of 2016 - through election night in early November - his election was very much in doubt. In 2017 - of which all twelve months followed his election by contrast, there was much more communicative license to assume (to make a WEAKER Assertion of) the shared Characterization of Trump as President (thus President Trump $=\mathrm{AB})$. See Table 1 .

Of course, both before and after the election and the inauguration, there would have been, on occasion, communicative reasons for a language-user to employ either order, so neither order was precluded at either time (thus no cell in the table is 0 ). For instance, in 2016, one could speak or write of an imagined future with an ensconced President Trump, and in 2017, one could still marvel at the course of events that made Trump President. Still, overall, between 2016 and 2017, the occurrences in COCA of Trump President $(\mathrm{BA}=$ STRONGER Assertion) and President Trump (AB = WEAKER Assertion) were about equal (7-6), whereas from 2016 to 2017 the occurrences of President Trump (the fait accompli) skyrocketed (from 111 to 4,006$)$. The numbers support the hypothesis. ${ }^{18}$ Furthermore, the observed pattern

Table 1. Pre- vs. post-inauguration Assertion of Characterization of Donald Trump as President.

\begin{tabular}{cccc}
\hline & BA (Trump President) & AB (President Trump) & Odds Ratio $^{\text {a }}$ \\
\hline 2016 & 7 & 111 & $>42$ \\
2017 & 6 & 4006 & \\
\hline
\end{tabular}

${ }^{\mathrm{a}}$ The odds ratio, $\mathrm{OR}$, which measure has a null value of 1.0 indicating no association, is provided merely as the most straightforward measure of the strength of association, with no implications about statistical generalizability to other bodies of discourse (i.e. about general validity), such as a statistical test (with a p-value) would have. See Davis 2002. 
calls into question the traditional assumption that there is a fixed order between a title and a proper name.

\subsubsection{Characterization that is contestable}

STRONGER Assertion is also useful when the context makes clear that various perspectives exist and the opinion inherent in the Characterization is contested and thus benefits from rhetorical emphasis. Views can vary not just through time but also from one person to another. In Example (10), the U.S. Federal Aviation Administration, a government agency tasked with regulating airline safety, has a different opinion about the placement of a superspeedway next to an airport than does Penske Motorsports Inc., a commercial enterprise with an agenda devoted to racing entertainment:

(10) Penske Motorsports Inc. approaches Adams County commissioners about building a superspeedway on 640 acres just south of Denver International Airport. Because the location will put crowds of people under planes landing at the airport, the Federal Aviation Administration deems the site (B) unsafe (A). (Arellano 2007)

Whereas the company Penske Motorsports finds the location appropriate to its needs, the FAA's opinion of the proposed location for the racetrack, ultimately the deciding factor in the placement of the speedway, is highlighted with the meaning STRONGER Assertion of Characterization: site $(B)$ unsafe $(A)$.

The word deems in Example (10) reinforces our view that this is an opinion that requires highlighting. Indeed, in general, a context involving the lexical item deem will tend to have an instance of the signal BA, as compared to a context involving for the sake of contrast - the lexical item recognize, which will tend to have $\mathrm{AB}$, as seen in Table 2. The word deem - "to have an opinion" (Webster's) - suggests the relevance of a particular speaker's subjective perspective. Conversely, recognize can be defined as "to perceive to be something previously known" or, etymologically, to "know again" (cf. §5.1.1 above). In recognize, one gets a sense of a shared perspective wherein someone "acknowledges" something, perhaps something already known by someone else.

If we accept that the phrase "deems the" indicates a higher degree of subjectivity than "recognizes the," then this leads to the prediction that the phrase "deems the" will co-occur more often with the BA signal, meaning STRONGER Assertion of the Characterization, than will the phrase "recognizes the." For a variety of reasons - the trait is not obvious or shared, it is summative, it reflects a contested opinion, etc. - the

Table 2. Deem favors STRONGer Assertion of Characterization, vs. recognize.

\begin{tabular}{lccc}
\hline & BA: STRONGER ${ }^{\text {a }}$ & AB: WEAKER & Odds Ratio \\
\hline "deems the" & 13 & 9 & $>23$ \\
"recognizes the" & 1 & 16 &
\end{tabular}

${ }^{\mathrm{a}}$ Here and in subsequent tables, numbers for BA include separated B ... A, including predicate adjectives. See $\S 5.4$ on nonadjacency. 
Characterization requires emphasis. Table 2 presents the results, with data from COCA.

In Table 2, in context with "deems the," the order BA is favored (13-9), while in context with "recognizes the," the same order is disfavored (1-16). In other words, relative to each other, "deems the" favors BA, and "recognizes the" favors AB. That association is consistent with our hypothesized meanings for the two orders: STRONGER and WEAKER Assertion of Characterization, respectively. The phrase "deems the" indicates a higher degree of subjectivity than "recognizes the," and so "deems the" exhibits a distributional preference for the BA order. The count lends support to the hypothesis. ${ }^{19}$

Another contrast in opinions rendered with STRONGER Assertion of Characterization, can be found in Example (11):

(11) Now, some might consider a few dozen incidents $(B)$ a year in a country of 4,583 higher education institutions a national $\operatorname{crisis}(A)^{20}$; I would consider it $(B)$ perhaps unfortunate $(A)$, but not a crisis. (Beauchamp 2018)

The meaning STRONGER Assertion of Characterization, employed twice here, helps the author to draw attention to two different opinions about the state of free speech on college campuses. The opinions exist in opposition to each other: "some" people characterize the incidents as a crisis, "but" the author ("I") views them instead as unfortunate.

\subsubsection{Characterizations that are unexpected but conclusive, that add heightened drama}

At times a text prepares the reader to arrive at a dramatic or unexpected Characterization of an entity in order to intensify and resolve the events of a narrative as it advances. Consider Example (12):

(12) A six-hour search for a 5-year-old boy $(B) \operatorname{lost}(A)$ in the woods behind his grandparents' Spotsylvania County home yesterday ended at dusk with hugs and tears from his relieved family ... "All of us got a little teary-eyed there for a minute," Smith said. "It's fantastic we found $\operatorname{him}(B) \operatorname{safe}(A)$ and sound." (Pugh 2002)

There is a search for a boy who has gone missing - is lost - and the search ends happily. The trait of his ultimately being found safe is Asserted forcefully with the meaning STRONGER Assertion of Characterization. ${ }^{21}$ That meaning relays an unexpected ("fantastic") Characterization - safe - that brings closure to the passage. In fact, the entire article revolves around the state of the boy's safety. Near the beginning of the excerpt, the boy's unsettling trait of being lost, which will turn out to be important, is thus postposed (boy lost); this sets the stage for the boy's eventually being found safe. (On the other hand, the boy's identification as a "5-year-old boy" - AB - is more weakly Asserted being that it is merely information that should be accepted on the author's journalistic authority.) In (12), the meaning STRONGER Assertion of Characterization helps, twice, to dramatize and emphasize the boy's misadventure, with an outcome that was less than assured, having required a six-hour search performed by dozens of volunteers. 


\subsection{Characterizations that incidentally involve a contrast}

Recall the position of Diver (1982), whereby the meaning of only one order (AB) had to do with differences "from other." In fact, both meanings - WEAKER and STRONGER Assertion of Characterization - are found in contexts involving a contrast between entities, or a situation involving differences "from other." A communicative need to differentiate one entity from another is an independent consideration from the strength of the Assertion of Characterization that might accompany such a differentiation.

Consider first the meaning WEAKER Assertion of Characterization, signaled by the $\mathrm{AB}$ order.

Example (13) comes at the very beginning of a story about a wife who cares for her husband at the end of his life and Characterizes the different days he experiences as he suffers with what appears to be dementia.

(13) He has his $\operatorname{good}(A) \operatorname{days}(B)$. Of course, he has his $\operatorname{bad}(A)$ days $(B)$, too, but let's not think about them for the moment. On his $\operatorname{good}(A) \operatorname{days}(B)$, I read to him. (Barnes 2004)

Clearly, two sets of days are here differentiated from each other, and that differentiation is said by the narrator to rest on the basis of the contrast between good and bad. The contrast, indeed, derives from those two lexical items, whose senses differ so starkly. The contrast does not come from the $\mathrm{AB}$ order.

The wider context of Example (13) reveals that, eventually, the days that had once seemed good to the narrator are in fact not so good, and the days that had seemed bad to her are in fact not so bad: On the days when her ailing husband is able to remember things, those things are sometimes disturbing to her; when he is unable to remember things, she can continue unperturbed in her beliefs. The operative factor in (13) is that the narrator, at the very beginning of the story, needs us to accept her Characterization of the two types of days on her authority at that moment (cf. §5.1.3 above): She is his wife and a nurse, after all, and so who are we to question her judgement? It is on the basis of that authority to Characterize that she makes a contrast between the days at that point in the story. Thus the meaning WEAKER Assertion of Characterization (AB) is the better choice. With the meaning WEAKER Assertion of Characterization, the reader is freed not to dwell on - to question - the Characterization of the days - it seems so inconsequential, so in keeping with our experiences with sick people but instead to follow the narrative as the narrator (the writer) wishes it to unfold in this case, so that the writer can relate subsequent events and trick the reader into questioning which really are the good days and which are the bad days.

An inference of contrast between entities on the basis of two different descriptors can also be had with the meaning STRONGER Assertion of Characterization. Consider Example (14), from a funeral oration. ${ }^{22}$ The excerpt below concerns the personal character of the deceased:

(14) Many of us knew the man well, especially by the affectionate acronym "PD". We have our own vivid and personal memories of days shared with him - days $(B) \operatorname{good}$ (A) and days $(B) \operatorname{bad}(A)$, days of laughter and days of effort and strain. Peter's life consisted of several important interdigitating parts, a little like a jigsaw puzzle. Few of us were familiar with all the pieces, and what is now written, must be inevitably partial, not comprehensive. However, we think that it will not be unrepresentative. Peter was a challenging man. (Tan et al. 2019) 
The orators take the view that the deceased was "a challenging man" with a personality consisting of "several important interdigitating parts, a little like a jigsaw puzzle." They say they knew the deceased over many years on two differently Characterized days - good and bad. Much of the remainder of the oration, in fact, has to do with that complicated personality. It must indeed have been the case that, in knowing the deceased, the orators experienced days that were different from one another. The differences get highlighted to emphasize the close, all-encompassing nature of the friendship. The Assertion of the Characterization of the two different types of days needs to be STRONGER so that the orator's point about the complex character of the deceased will come across clearly.

Actually, an inference of contrast can be had without either of our signals:

Person 1: "How were your days before your promotion?"

Person 2: "Good."

Person 1: "And how were your days after your promotion?"

Person 2: "Bad."

Again, there are two differently Characterized sets of days - good and bad-but there is neither an $\mathrm{AB}$ nor a $\mathrm{BA}$ order. ${ }^{23}$

It is not the function of the $\mathrm{AB}$ order to differentiate one referent from another. Any inferences of contrast and comparison derive from other ingredients in the context, such as, in (13) and (14), from the senses of the lexical items good vs. bad, not from the word order. Contrasts may well be inferred, whether or not there are obvious candidates for contrasting elements (as in 13 and 14) or merely imaginable candidates (as implied in previous examples). Consider above: Example (1) little girls vs. hypothetical big girls, one of which June will someday be; (2) dead wife vs. living wife, which the woman used to be; (3) long hair, bare chest, tight pants vs. short hair, covered chest, loose pants, attributes that some people possess, and that even Robert Plant might at times possess; (4) classic summer vs. ho-hum summer, something people don't write books about; (5) best restaurants vs. crummy restaurants, the places where less celebrated cooks work; and (6) Crooked Hillary Clinton vs. - well, presumably not some other Hillary Clinton. The AB signal is not contrasting but doing something else: signaling the relative strength of the writer's Assertion of the Characterization. Assertion of Characterization is independent of differentiation among entities.

\subsection{Nonadjacency}

As already seen in Example (11) (incidents ... crisis) the postposing of the Characterizing trait (A) occurs, at times, at a distance from the entity it Characterizes (B). The meaning STRONGER Assertion of Characterization applies even when the parts of the signal are nonadjacent. ${ }^{24}$ Though the components of the signal may be separable, with various intervening words and structures, the signal's meaning is not different from what we have already seen.

In this regard, consider the following examples, beginning with (15):

(15) Elizabeth $(B)$ had been more distraught than anyone else and had left the table angry

(A) at both men .... [She later] apologized for her behavior and rejoined the group for dessert and small talk. (Walley 2013) 
The attribute angry describes Elizabeth - and not the table, though that word is adjacent - as she reacts to upsetting events. As in Example (8) (door unlocked), here the meaning STRONGER Assertion of Characterization is consistent with the advancement of the narrative. Elizabeth's angry state requires STRONGER Assertion because that Characterization accounts for her subsequent actions: She leaves the table and later apologizes.

One common reason for there being intervening words between the two parts of the signal (B ... A) is the presence of other information relating to the $\mathrm{B}$, that is, a so-called heavy noun phrase. Consider Example (16), from a speech given by the Head of Delegation of the European Union. In it, the speaker addresses her audience about the European Union's role as a "global actor" that is "deeply engaged in the setting of standards and upholding of principles" and turns her attention to the recent annexation of the Crimean peninsula (a Ukrainian territory) by Russia:

(16) We do not recognize the referendum in Crimea and consider the annexation $(B)$ of Crimea and Sevastopol by Russia illegal $(A)$. There must be a return to international legality. (Zappia 2014).

As in Examples (10) (site unsafe) and (11) (incidents ... crisis), the speaker's choice to give a STRONGER Assertion of the Characterization of Russia's action, the annexation, as illegal reflects her awareness that this is a disputed opinion (Russia, in particular, does not agree with her). With the postposing, she emphasizes the importance of the selected trait, consistent with her awareness that the opinion is contestable, and makes her stance firm: She is a representative of the European Union, arguing in favor of a return to established "international legality."

Furthermore, the BA signal often coincides with other language features that stand between the $\mathrm{B}$ and the $\mathrm{A}$ that act to intensify the Characterization or introduce elements of degree (both of which heighten the subjectivity of a Characterization). The use of intensifiers, such as comparatives (more or -er) or adverbials (e.g. so and very), provides additional emphasis for the Characterizing traits in a way that is consistent with our proposed meaning.

In Example (17), below, the narrator's perspective is on display in describing the towns' names. The STRONGER Assertion of Characterization coincides effectively with the intensifier so and heightens the subjectivity of the message.

(17) I had been to Los Angeles a dozen times, and further, up the coast to Malibu and Zuma and Ventura, names(B) so beautiful ( $A$ ) you'd think they were someplace else. (Patchett 2011)

Because the nature or degree of beauty for the names of towns is subjective, the Characterization in this example requires STRONGER Assertion to stress just how beautiful the names are. The beauty of the town names is not contextually apparent; the Characterization is a subjective opinion that is highlighted through postposing as well as the intensifying so.

The pattern is general; the data in Table 3 come from COCA.

The odds of a BA signal co-occurring with the word beautiful preceded by more are over ten times as high as the odds of a BA signal co-occurring with beautiful unmodified. 
Table 3. Presence of comparative more with beautiful favors STRONGER Assertion of Characterization $^{\mathrm{a}}$.

\begin{tabular}{lccc}
\hline & $\mathrm{BA}=$ STRONGER & $\mathrm{AB}=$ WEAKER & Odds Ratio \\
\hline more beautiful & 33 & 5 & $>10$ \\
unmodified beautiful & 17 & 27 & \\
\hline
\end{tabular}

${ }^{\mathrm{a}}$ In COCA, more beautiful (the first 50 tokens) compared with beautiful unmodified (the first 50 tokens). As in previous tables, not all tokens in the corpus will co-occur with an instance of BA or AB. Similar results were obtained for very beautiful.

As with the above cases where noun phrases or intensifiers intervene between the two parts of the signal, at times the nonadjacency of the B and A arises out of the presence of a linking verb. Huffman (2002), offering as we do a signal-meaning hypothesis, accounts for the word order of an entity and the verb (a subject and verb) as a matter of "Focus," whereby the noun-verb / verb-noun orders specify the degree of attention to a "complex" or "cluster" of information that includes a participant (P) and an event (E) (pp. 322-323). The order PE, as in An explanation comes first, signals MORE Focus on the cluster An explanation comes, and the order EP, as in First comes an explanation, signals LESS Focus on the cluster comes an explanation. Huffman validates his hypothesis using authentic examples in context (as in our case, the only way to validate such a hypothesis).

This interposing of the "event" or linking verb between the word for an entity (Huffman's PE) and its Characterization, through the meaning MORE Focus, directs readers to pay attention; this prepares them for (and facilitates their recognition of) the STRONGER Assertion of Characterization signaled by our BA signal. That is, in an example such as June took sick (18, below), we have both a PE signal (June took) and a BA signal (June ... sick). Thus a reader's Focus, or attention, is heightened in advance of the Characterization. As seen with the previous Examples (8) (door unlocked) and (15) (Elizabeth ... angry) and now here again with Example (18), the meaning STRONGER Assertion of Characterization is used to draw the reader's attention to a Characterization that is essential to the progression of the narrative and so is Asserted more forcefully.

(18) June [was like] many little girls ... . Then little June took sick ( $P E$ and $B A)$ and laid $[s i c]$ in her bed like a dull penny .... She was slipping away so fast you could all but see her dying right before your eyes, and there sat her parents not a thing in the world to do. So George [June's father] goes out in the middle of the night ... . He prays. He takes [a] drink .... He lifts up June's head .... He wonders. (Patchett 2011)

June's Characterization as sick is given a STRONGER Assertion because it is a crucial detail around which the subsequent plot develops. Greater context for the story (than what is provided here) makes it clear that June's illness sparks a series of actions in her father, which indeed set the stage for the entire rest of the novel.

Because our BA signal works to communicate contextually essential description requiring STRONGER Assertion, it seems reasonable that, as is well-known, it often overlaps in discourse with the signal PE indicating MORE Focus ${ }^{25}$ (the predicate 
adjective construction): The two meanings are working in concert to elevate even more effectively the significance of the overall Characterization. That is, it is for semantic reasons that $\mathrm{PE}$ and $\mathrm{BA}$ often co-occur.

Such is the case in Example (19), a continuation of the passage in (18), where the Characterization provides information that dramatizes the event and heightens its impact in the narrative - as it also did in the adjacent him safe of Example (12). After almost dying from her illness, June's sudden recovery is communicated with greater force by the meaning STRONGER Assertion of Characterization:

(19) The next morning June is fine (PE and $B A$ ), perfect, better than new. (Patchett 2011)

June's new Characterization (after context has established her as deathly ill) as fine is important, dramatic, worthy of Focus (PE June is) because - as revealed in the context of the subsequent novel - her recovery changes June's life, her father's life, and indeed the fate of the town. The unexpectedness of her survival is essential to a larger message (of miracles, redemption, faith, etc.) that Patchett's novel will spend several hundred pages communicating. June's Characterization deserves the meaning STRONGER Assertion (BA) just as her new state deserves the meaning MORE Focus (PE): It brings that information to our attention and prepares us for what follows in the novel.

The sequence of signaling elements $P=\mathrm{B}$ E A, as in Example (19) June $(P=B)$ is (E) fine $(A)$, is not the only permutation that signals both the meaning MORE Focus and the meaning STRONGER Assertion of Characterization. The sequence $P=\mathrm{B}$ A E also occurs, as in Example (20), below. This passage is from informational material by an organization that works to prevent teenage suicide.

(20) What is a life worth to you? We desperately need your help to build up our Youth Assistance Fund. And it won't cost you a dime! Just use the Arizona Tax Credit to allocate some of your taxes to The New Foundation. A $\operatorname{child}(B=P) \operatorname{lost}(A)$ is $(E)$ a wasted life. The New Foundation provides a kid-focused environment where young people can heal from emotional wounds and build strength for the future. Please help us create happy endings for families. (The New Foundation 2018)

Here, MORE Focus (with the PE signal) is directed to the status of a child with its Characterization (lost) already Asserted: child lost is. That Characterization is an essential part of the information package and thus elevated. Attention (MORE Focus) is given to the status of an entity and its Asserted attribute together (child lost is), to prepare the reader for even further Characterization ( $a$ wasted life). A child lost to suicide is not just a child lost; it is, moreover, a wasted life. ${ }^{26}$ There is not just the matter of past "emotional wounds" but also of the forever unrealized potential of that child's "future." The ad-writer's goal is to galvanize an emotional response. Because child suicide is so dire, the Foundation, according to the ad, deserves readers' monetary support.

The semantic difference, then, between Examples (19) and (20) lies in where, exactly, the meaning MORE Focus kicks in (where the $i s$ is): on the entity uncharacterized (June) before it is given a STRONGER Assertion of Characterization (fine), or on the entity already strongly Characterized ( $a$ child lost) before it is given yet another STRONGER Assertion of Characterization (a wasted life). 


\section{Issues for future research}

Certain issues are excluded from this study because the types of examples involved do not contain an instance of the signals posited here; our signal is absent, and so the examples are outside our scope. Other questions for future research involve refinements to treatments given here.

\subsection{Absence of the signal}

\subsubsection{Non-finites and absolute position}

One class of examples omitted from this study because these do not involve our posited signals is represented by predicating non-finites. These, by definition in modern English, typically lack any overt subject to serve as the B in a BA signal. For instance: Be nice! (imperative); Feeling sick, she went home (participle); and To grow strong, he exercised (infinitive). It would indeed seem that words such as nice, sick, and old are descriptive, but the person so described (if there even is one) is left unmentioned. There might appear to be an $\mathrm{A}$, but there is no $\mathrm{B}$, thus no $\mathrm{BA}$ (or AB) signal. Not grammatical signaling but inference alone must be at work here. The same may be true for descriptive words in any absolute position, such as those bracketed in writing by commas, as in Uncertain, I hesitated.

\subsubsection{Quantifiers and ordinals}

Likewise, the semantic substance of Assertion of Characterization is not involved in expressions having to do with quantification or ordering. These can be represented by phrases such as three times, much love, ninth inning, and by Game Seven. In these phrases, the words three, much, ninth, and Seven do not Characterize so much as quantify or identify by means of order in a series. They say nothing about the nature - the characteristics - of the times, love, inning, or Game (by contrast, consider good times, unrequited love, disastrous inning, exciting game). Moreover, there are morphological clues that these need to be excluded from the present study. The adjective-like words that occur in position before the noun-like words (what might appear to be ABs) do not get relativized: *three-ish times, *mucher love, *ninthest inning. ${ }^{27}$ And, with the adjective-like words that occur in position after the noun-like words (what might appear to be BAs), the signal of grammatical number (Reid 1991) may get attached to the final (second) word of the string rather than the first word of the string:

Game $7 \mathrm{~s}$ are often unforgettable and produce some of the best moments in baseball history. ${ }^{28}$

Evidently, Game 7 is the name of the game; that is what gets pluralized. And while a Game 7 is certainly a different game from a Game 6 - as a ninth inning is a different inning from an eighth inning - distinguishing one referent from another is not, as we have seen, the essential function of this system.

\subsubsection{Adjectives outside the [det]-B frame}

A third type not treated in this analysis because it does not contain an instance of the signals posited here can be represented by: 
In such examples, the characterizing word (unelectable here) appears outside the determiner-noun complex (any candidate), that is, positionally before the B (candidate) yet not in the proper place to be counted as a component of an AB signal. Moreover, the effect in the message does not seem to be equivalent to that achieved by an $\mathrm{AB}$, as it does in the sentence below, which does contain a legitimate AB signal:

I will not consider casting my vote for any unelectable candidate.

The status of such orders as in the former must be left for future research. It may be that language processing is an issue since the position of the modifier seems to correlate with the length (the weight) of the modified phrase.

\subsubsection{Text-Structuring}

A rich area for further research involves what might appear to be a permutation of the order commonly observed in what are widely known as predicate adjectives (Ex. 19, June is fine). Recall that such examples were covered above as legitimate instances of the signal BA, meaning STRONGER Assertion of Characterization. One might well wonder how to treat what might appear to be an opposing type, with what looks like an A separated from its B by a verb but with the A occurring before the $\mathrm{B}$, as in Heavy is the burden. That type is excluded here for three reasons.

One, the type does not represent an instance of either signal posited here, since the description that would be the A - but let us call it "X" - (e.g. heavy) occurs outside the determiner-B matrix, or the noun phrase: $\operatorname{Heavy}(X)$ is the burden; refer again to Figure 1.

Two, the meaning that would presumably be signaled by the AB order (WEAKER Assertion of Characterization) seems to be quite inappropriate in such examples. In traditional rhetorical terms, the description (e.g. heavy) seems, if anything, more predicative than attributive. Intuition suggests that, if anything, this is more of a BA-type message than an AB-type message. Analysis of these examples alongside ours might well prove fruitless, and so we do not muddy the waters here.

Three, examples such as Heavy is the burden are not comparable to examples such as June is fine in that the orders of subject and verb are different: the order June is (PE) versus the order is the burden (EP). Those two orders, as explained above, are what Huffman (2002) treats as signals of opposing meanings in a system of Focus. So while examples such as June (P) is (E) fine signal MORE Focus on the cluster June is, by contrast Heavy is $(\mathrm{E})$ the burden $(\mathrm{P})$ signals LESS Focus on the cluster is the burden. The two types of examples are not comparable.

Preliminary investigation of attested examples of the type Heavy is the burden suggests that these must be accommodated within Huffman's (2002) typology of examples that involve "preposing" (our X), wherein "preposing facilitates processing by helping to structure the text." The examples we have seen - and they are not so rare - can be divided into roughly three rhetorical types: scene-setting, transitioning, and taking stock. Noting those types here may help with future research.

\subsection{Problematic identification of the signal}

Further research is also called for regarding a few issues that do or may fall within the scope of this study. 


\subsubsection{Compound noun phrases}

A sort of complementary type to non-finites (§6.1.1) is made up of examples where not the thing described (the B) but instead the descriptive word (the A) is omitted. One classic example is the phrase (the) old men and women. Such were treated in early modern syntax (Chomsky 1957: 87) as a matter of different underlying constituent structures (in one of which the women are old and in the other of which the women are not necessarily old). The scope of the adjective is ambiguous. A reader or listener of such a phrase can only use inference in context to resolve the ambiguity: Does the A Characterize the second B or not? Granted, grammatical signals must in general be inferred, but these cases present a particular challenge in verification.

\subsubsection{Personal and indefinite pronouns}

We see no reason to assume that there is a class of words - pronouns as distinct from nouns - that are not accommodated by our hypothesis. It appears that words like you, him (Ex. 12), anyone, and something - personal and indefinite pronouns - can indeed function as B to an A.

While there do exist examples where pronouns are Characterized with a preposed attribute (a new you; a special something) and so participate in signaling the meaning WEAKER Assertion of Characterization (AB), such cases are fairly rare. Far more commonly, pronouns - both personal and indefinite - precede any modifier, thus participating in the signaling of the meaning STRONGER Assertion of Characterization (BA).

Although personal and indefinite pronouns might seem to be diametrically opposed in terms of referential specificity, in fact, what the two have in common, in communication, is that they specify a referent to just the degree that the languageuser wishes. (Think of personal vs. impersonal you, or thing in that thing vs. something.) Referential specificity has to do with the scene (in Diver's sense); our interest here lies instead in the language-user's shaping of discourse: the use of meanings to convey a message. With a word like you or something, any additional Characterization will be new, extra, often an advancement of the narrative. That communicative specialization (versus a typical generic noun) accounts for the stark preference by both types of pronouns for STRONGER Assertion of Characterization (BA).

\subsubsection{Adjective or noun?}

Similarly, it appears that no distinction needs to be made between adjectives and nouns in terms of how they behave vis-à-vis this grammatical system (e.g. I love a blue sky / I painted my walls a sky blue). Nevertheless, it is true, in usage and in analysis, that the decision as to which word is the A and which the B is not always clear.

With certain couplings of words it is more difficult to specify for sure which word Characterizes which. This is particularly a challenge when both lexical items could, in usage, be classifiable as nouns and so either could refer to the thing Characterized, and either or both may vary in grammatical number. Validation of the hypothesis here would be especially vexing with data that include examples of what in the tradition would be called predicate nouns. However, in our experience, context will typically help an analyst (or listener or reader) to make a decision as to whether such a token is an instance of our BA or instead an instance of text structuring in conjunction with the verb-subject order $(\mathrm{X}+\mathrm{EP})$ : 
No, he's not a Republican; Andrew Cuomo is a Democrat (PE and BA).

Next on our list, another Democrat is Andrew Cuomo (X+EP).

It is also possible for a predicate noun to be modified, as in He was the quintessential hard rock front man (from Ex. 3). The AB here may identify a known type (hard rock front man), of which something $(\mathrm{He})$ is asserted, with the signal BA = STRONGER, to be a token. ${ }^{29}$ When the general problem of the analysis of examples of predicate nouns is undertaken, the problem of their internal modification must be explored fully.

Another sort of example that is omitted from this study - again only because of the preexisting obstacle of the canon of parts of speech - is the type that in traditional grammar would be considered that of an adjective used as a noun, as in Sometimes dead is better. ${ }^{30}$ Presumably, such do represent an instance of our BA signal (dead ... better).

\subsubsection{Adjectives in a-}

At first glance, accounting for the position of words such as alive in phrases such as sexiest man alive would appear to fall under the scope of the present problem. (The opposite order is also attested, if uncommon: alive grannies.) However, such phrases may lie outside the scope of this study. There exists a class of words beginning phonetically in schwa and followed by a separable, stressed, potentially freestanding morpheme of related sense that routinely appear in what looks like our BA order but without the communicative effects we have associated with the meaning of that order. The usage of such words, however, spans a range far from limited to Characterization of an entity, classed instead (in dictionary entries) as some combination of adjective, adverb, preposition, verb, and noun. ${ }^{31}$ Words such as alive may need to be analyzed alongside words and phrases (particularly prepositional phrases) not covered in the present study.

\section{Conclusion}

In English the orders of Characterizing words with respect to the words they Characterize (adjective-noun and noun-adjective orders) function as meaningful signals that writers employ in order to direct the reader, with either greater or lesser intensity, to accept the Assertion of the Characterization. At each opportunity, writers choose a level of intensity in keeping with their larger communicative goals in discourse. Insight into this communicative mechanism of the grammar may help to elucidate the order of words in several related cases.

\section{Acknowledgements}

Thanks to the participants in the Seminar on Columbia School Linguistics at Columbia University for their encouragement and feedback on the research that led to this paper; Eduardo HoFernández, in particular, provided useful references. The Columbia School Linguistic Society awarded graduate research fellowships to one of us (Author One) for research that led to this paper. The School of Education of The City College of New York awarded another of us (Author Two) release time for work on this project.

\section{Disclosure statement}

No potential conflict of interest was reported by the author(s). 


\section{Notes}

1. For a critique of the relation between Saussure's constructs and ours (from William Diver passim), see Davis (2004: 316-324).

2. When, as is the case with the components of our hypothesized signals, there are only two items, the relationships of order and position coincide, but in general the two relationships are not exactly the same thing. For instance, the order of the overt syntactic objects would be notated differently for English finites (They give me the money) and non-finites (Giving me the money, ... ): for finites, "second" and "third" in order, respectively, versus, for nonfinites, "first" and "second" in order. On the other hand, the position relative to the verb could be notated identically for finites and non-finites, such as by "following immediately" and "following not immediately" (cf. Diver and Davis 2012: 239-245). For the purposes of this paper, order and position coincide.

3. This paper, following Columbia School practice, indicates formally hypothesized meanings in small capital letters and the names of semantic substances with initial capital letters.

4. This paper does not undertake to specify exactly what words in English can function as determiners, but analysis suggests that they include: $a(n)$, the, any, those, $m y$, and so forth.

5. As will become evident, we rely heavily in this paper upon written discourse, and so we often refer to "reader" and "author," but our hypothesis appears to apply as well to listener and speaker.

6. For this system to be a viable communicative tool, it must be the case that listeners (or readers) can typically decide which word (the A) Characterizes which (the B); otherwise, there would be no way to distinguish the two orders.

7. This formulation avoids reference to traditional parts of speech (blue sky / sky blue). Cf. fn. 6 .

8. An incisive critique of Halliday and Hasan (1976) and of the relevance of - and irrelevance of - the study of cohesion to the analysis of linguistic elements is provided by Reid (1991: 307-309). In his analysis of the grammatical signals of Number in English, Reid notes that signaled meanings of grammatical Number - the things that he posits - can indeed contribute to what he calls "textual resonance," but for him - and for us - the message in a text is a gestalt, not analyzable into discrete fractions (e.g. the contributions of individual words).

9. "Temporal spread," which is semantic, is actually only one of two "solutions" that Bolinger proposes; the second - reflecting the generative mindset of that day - has to do with the syntactically underlying source, through "generation," of two types of modification.

10. One realizes too that the notion of "possible worlds" cannot but represent an enormous analytical escape hatch and abandons the testability of a hypothesis, since a languageuser (such as a novelist or a liar) can imagine and represent any world he or she wishes, whether the analyst knows that world is real or not.

11. William Diver was editor of the journal WORD from 1956 to 1965. The 2012 volume was edited and published posthumously. An analysis of Diver's work is treated in Davis (2016).

12. Given language variation (even to the point of idiolects), it is a real analytical question just what language-users - and thus what data - will be admitted into one's data set. See Davis (2017b), particularly his discussion on pp. 241-242, for one way to handle that challenge.

13. One of us (Author Two) for several years taught Diver's hypothesis at the university level, until extensive work with actual text, in collaboration with graduate students, led to a different hypothesis involving the two orders: that the order BA signals that Alternative Characterization is to be CONSIDERED while the order AB signals that it is NOT CONSIDERED. That revision, in turn, led to the present hypothesis (primarily by Author One).

14. The analysis of Diver's work that is summarized here is not published in Huffman and Davis (2012).

15. In light of our definition of the signal as "[det] AB" in Diagram 1, it may help to make it explicit here that we assume the existence of meaningful null articles (one singular and one plural) in position before such examples as Ø little June (cf. a little June such as we had never seen) and Ø many little girls (cf. the many little girls who came to the party), as well as in such examples as (Ex. 3, below) Ø lead singer, Ø long hair, Ø bare chest, Ø tight pants. Such a postulation is by no means unusual, but see Huffman (2001: 56) for the analysis (by Diver) that we assume here. 
16. A reminder that this paper does not investigate any differences between the orders of descriptive words such as classic American summer / American classic summer, let alone long, classic American summer.

17. The count was conducted in November 2017. See footnotes 6 and 7 regarding our handling of parts of speech.

18. Counts in this paper are offered as support for our hypothesis, not as discoveries in their own right. For previous use of quantitative data in support of a signal-meaning hypothesis see Diver (1987/2012: 93-95), Reid (1991: 363), Huffman (1997: 73, 163, 234), Reid (2011: 1098-1099, 1109-1110, 1120-1126), Davis (2017a: 110-114), Davis (2017b: 48-49, 57, 70, 77), and Sabar (2018: 21-22 et passim). This may be, however, the first use within this framework of time as an independent variable.

19. An exhaustive search in COCA yields 59 tokens of the phrase "deems the" and 1,382 tokens of "recognizes the," most of which contain neither a BA nor an AB (these do not appear in Table 2). The word the is included simply to focus the mechanical count on a following noun phrase.

20. See footnotes 6 and 7 as well as the section on Issues for Future Research (\$6) for our handling of parts of speech.

21. Again, in this treatment, we do not treat nouns and pronouns differently, as the hypothesis appears to apply to both equally. See $\$ 6.2 .2$ regarding the strong tendency for the modification of pronouns to appear in the BA order (e.g. him safe).

22. An anonymous reader offers the intriguing suggestion that formal, prepared spoken discourse (as opposed to, say, spontaneous speech) may exhibit patterns of usage that resemble published written discourse. In particular, in those two communicative settings, the signal (BA) of the meaning STRONGER Assertion of Characterization may be more frequent than it is in, say, spontaneous speech. If so, that could well have to do with a languageuser's awareness of a relative dearth of shared situational knowledge between writer/ orator and reader/listener (as opposed to casual interlocutors).

23. In general in this paper, constructed passages are used purely for illustrative purposes; we analyze only attested examples. See also §6.1.1.

24. Adjacency is also an irrelevant consideration with order (or positional) signaling in several of the previous analyses cited above, including in Huffman (2002), cited extensively below. The issue of adjacency does not come up with the [det] AB signal, even in the case of strings of A's (e.g. a long, hot summer): there all the A's are confined between the [det] and the B, not separated from the B by a different grammatical signal.

25. Alongside the first 100 tokens of AB in Patchett (2011), there were only 18 unseparated BA but 68 separated by a linking verb (e.g. was, became).

26. See $\$ 6.2 .3$ below regarding modification within a predicate noun (as in a wasted life).

27. In this paper, we employ the asterisk not in the generativist sense of "ungrammatical" (i.e., not generated by the grammar) but in the sense of "unattested" in our data. That is, we make no claim at all that, given human ingenuity, certain things cannot be said. For instance, imagine someone saying Gee, that was the ninthest ninth inning I've ever seen!

28. https://fansided.com, accessed November 2, 2016.

29. Thanks to CCNY graduate student Edward Berk for this insight.

30. Paramount Pictures. 2018. Pet sematary official trailer.

31. These words include: abed, abroad, across, adrift, afloat, afoot, ahead, alive, alone, apart, around, askew, asleep, astray, atilt, atop, awake, awash, and away.

\section{References}

Arellano, Kristi. 2007. Speedway talks just starting to warm up. The Denver Post. 14 February. Asher, Nicholas, Tim Van de Cruys, Antoine Bride, and Márta Abrusán. 2016. Integrating type theory and distributional semantics: A case study on adjective-noun compositions. Computational Linguistics 42(4). 703-25.

Barnes, Julian. 2004. The lemon table. New York: Vintage International.

Barwell, Tom. 2012. Comic books. Merritton Matters 8(2). 13. www.merrittonmatters.ca.

Beauchamp, Zack. 2018. The myth of a campus free speech crisis. Vox. 31 August. 
Boleda, Gemma, Marco Baroni, Louise McNally, and The Nghia Pham. 2013. Intentionality was only alleged: On adjective-noun composition in distributional semantics. Proceedings of the 10th International Conference on Computational Linguistics, 35-46. Potsdam: Association for Computational Linguistics.

Bolinger, Dwight. 1967. Adjectives in English: Attribution and predication. Lingua 18. 1-34.

Bourdain, Anthony. 2000. Kitchen confidential. London: Bloomsbury Publishing.

Brown, Jeffrey. 2017. Robert Plant's new album follows the 'Fire' of his musical passions. PBS Newshour. 13 November.

Chomsky, Noam. 1957. Syntactic structures. The Hague: Mouton.

Davidse, Kristin, and Tine Breban. 2019. A cognitive-functional approach to the order of adjectives in the English noun phrase. Linguistics 57(2). 327-71.

Davis, Joseph. 2002. Rethinking the place of statistics in Columbia School analysis. In Wallis Reid, Ricardo Otheguy, and Nancy Stern (eds.), Signal, meaning, and message: perspectives on sign-based linguistics, 65-90. Amsterdam / Philadelphia: John Benjamins.

Davis, Joseph. 2004. The linguistics of William Diver and the linguistics of Ferdinand de Saussure. In Gerda Haßler and Gesina Volkmann (eds.), The history of linguistics in texts and concepts Vol. 1. 307-26. Münster: Nodus.

Davis, Joseph. 2016. Latin nominatives with and without verbs. WORD 62(2). 91-108.

Davis, Joseph. 2017a. The semantic difference between Italian vi and ci. Lingua 200. 107-21.

Davis, Joseph. 2017b. The substance and value of Italian si. Amsterdam / Philadelphia: John Benjamins.

Diver, William. 1975/2012. The nature of linguistic meaning. In Alan Huffman and Joseph Davis (eds.), Language: communication and human behavior. The linguistic essays of William Diver, 46-63. Leiden / Boston: Brill.

Diver, William. 1982. The grammar of modern English. New York: Columbia University Department of Linguistics, unpublished MS.

Diver, William. 1987/2012. The dual. In Alan Huffman and Joseph Davis (eds.), Language: communication and human behavior. The linguistic essays of William Diver, 87-99. Leiden / Boston: Brill.

Diver, William. 1990/2012. The elements of a science of language. In Alan Huffman and Joseph Davis (eds.), Language: communication, and human behavior. The linguistic essays of William Diver, 65-84. Leiden / Boston: Brill.

Diver, William. 1995/2012. Theory. In Alan Huffman and Joseph Davis (eds.), Language: communication and human behavior. The linguistic essays of William Diver, 445-519. Leiden / Boston: Brill.

Diver, William, and Joseph Davis. 2012. Latin voice and case. In Alan Huffman and Joseph Davis (eds.), Language: communication and human behavior: The linguistic essays of William Diver, 195-245. Leiden / Boston: Brill.

Diver, William, Joseph Davis, and Wallis Reid. 2012. Traditional grammar and its legacy in twentieth-century linguistics. In Alan Huffman and Joseph Davis (eds.), Language: communication and human behavior: The linguistic essays of William Diver, 371-443. Leiden / Boston: Brill.

Gardenfors, Peter. 2000. Conceptual spaces: The geometry of thought. Cambridge: MIT Press.

Gildin, Bonny. 1989. Subject order in French: A signal-meaning analysis. New York: Columbia University Ph.D. dissertation.

Halliday, Michael A. K., and Ruqaiya Hasan. 1976. Cohesion in English. London / New York: Routledge.

Huffman, Alan. 1997. The categories of grammar: French lui and le. Amsterdam / Philadelphia: John Benjamins.

Huffman, Alan. 2001. The linguistics of William Diver and the Columbia School. WORD 52. $29-68$.

Huffman, Alan. 2002. Cognitive and semiotic modes of explanation in functional grammar. In Wallis Reid, Ricardo Otheguy, and Nancy Stern (eds.), Signal, meaning, and message: perspectives on sign-based linguistics, 311-37. Amsterdam / Philadelphia: John Benjamins.

Huffman, Alan, and Joseph Davis (eds.). 2012. Language: communication and human behavior: The linguistic essays of William Diver. Leiden / Boston: Brill. 
Klein-Andreu, Flora. 1983. Grammar in style: Spanish adjective placement. In Flora KleinAndreu (ed.), Discourse perspectives on syntax, 143-79. New York: Academic.

Paradis, Carita. 2008. Configurations, construals, and change: expressions of degree. English Language and Linguistics 12(2). 317-43.

Patchett, Ann. 2011. The patron saint of liars. New York: First Mariner Books.

Prince, Ellen F. 1981. Toward a taxonomy of given-new information. In Peter Cole (ed.), Radical pragmatics, 223-55. New York: Academic Press.

Pugh, Kari. 2002. Lost boy is found safe after straying with dog. www.Fredericksburg.com, April 2.

Quirk, Randolph, Sidney Greenbaum, Geoffrey Leech, and Jan Svartvik. 1985. A comprehensive grammar of the English language. London: Longman.

Reid, Wallis. 1991. Verb and noun number in English: A functional explanation. London I New York: Longman.

Reid, Wallis. 2006. Columbia School and Saussure's langue. In Joseph Davis, Radmila J. Gorup, and Nancy Stern (eds.), Advances in functional linguistics: Columbia School beyond its origins, 17-39. Amsterdam / Philadelphia: John Benjamins.

Reid, Wallis. 2011. The communicative function of English verb number. Natural Language and Linguistic Theory 29. 1087-146.

Rivera, Lilliam. 2019. In praise of Esmeralda Santiago. The New York Times, 11 April.

Sabar, Nadav. 2018. Lexical meaning as a testable hypothesis: The case of English look, see, seem and appear. Amsterdam / Philadelphia: John Benjamins.

Saussure, Ferdinand de. 1915/1972. Cours de linguistique générale. Paris: Payot.

Stern, Nancy. 2006. Tell me about yourself: A unified account of English -self pronouns. In Joseph Davis, Radmila J. Gorup, and Nancy Stern (eds.), Advances in functional linguistics: Columbia School beyond its origins, 177-94. Amsterdam / Philadelphia: John Benjamins.

Stern, Nancy. 2018. Ditransitives and the English system of Degree of Control: A Columbia School analysis. In Naomi L. Shin and Daniel Erker (eds.), Questioning theoretical primitives in linguistic inquiry, 157-88. Amsterdam / Philadelphia: John Benjamins.

Tan, Kit, Phillip Smith, and M. Yeoman. 2019. Obituary for Peter Hadland Davis. The Royal Society of Edinburgh. Online: https://www.rse.org.uk/cms/files/fellows/obits_alpha/davis_ peter.pdf, accessed July 2, 2019.

Taylor, John R. 1992. Old problems: adjectives in cognitive grammar. Cognitive Linguistics 3(1). $1-36$.

The New Foundation. 2018. Help us prevent teen suicide. Online: http://thenewfoundation.org/ help-us-prevent-teen-suicide/, accessed April 17.

Tomkins, Calvin. 2004. Summer afternoon. The New Yorker, 48-55. September 2004.

Trump, Donald. 2016. Crooked Hillary Clinton is unfit to serve as President of the U.S. Her temperament is weak and her opponents are strong. BAD JUDGEMENT! @realDonaldTrump. July 5, 2016, 9:36 pm. Tweet.

Walley, Keith. 2013. Bloodguilt. Online: www.Lulu.com, accessed April 13, 2020.

Yahr, Emily. 2014. Lily James had dyed her hair. The Washington Post, 26 December.

Zappia, Mariangela. 2014. The European training course on security policy. Speech, 3 April. GCSP European training course. Geneva. 